\title{
Qualitative and quantitative criteria for comfortable urban public spaces
}

\author{
S. Reiter \& A. De Herde \\ Architecture et Climat, Louvain-la-Neuve, Belgique
}

ABSTRACT: This research is dedicated to comfort in urban public spaces. Its main object is to outline the importance of a microclimatic study in urban places, in the framework of sustainable development of the cities. A quantitative approach is insufficient for the study of comfort in outdoor zone. Based on a literature survey of various comfort criteria and on an analysis of the psychological point of view of human comfort, this study enabled us to work out a new approach of comfort in urban public spaces, integrating quantitative limits and qualitative criteria. It is necessary to stress the importance of qualitative comfort criteria, such as relation with the context, perception of potential control, microclimatic environments diversity, continuity of climatic conditions and naturality of the place.

\section{INTRODUCTION}

Today, it is obvious that the Western model of development practised for a few decades has generated a lot of environmental and social damage whose extent appears only gradually. These problems decrease our life quality and seriously limit future generations' potential. Each of us has to recognize its share of responsibility in the evolution of our environment. Let us note the importance of the natural, built and human components of the environment. It is high time that we feel responsible for a more harmonious development of our natural and cultural heritage.

In an increasingly urbanised society, the urban environment's quality becomes one of the main targets of a sustainable development. It is thus necessary to examine all aspects of urbanistic and architectural design which influence people's comfort, energy management and built-up areas quality. How to control the environment and create the best conditions for human activities is a question as old as humanity itself. However, modern cities have been strongly influenced by economic values: the environmental quality of the spaces left between the buildings was seldom taken into account. Now, it is time to change the selection criteria for urban projects. Cities' sustainable development mainly depends on the capacity of the town planners to offer outdoor urban spaces with high environmental qualities. These enrich life experience downtown.

Designing and modifying urban forms induce major and long-term transformations to the environ- ment. The microclimate is one of the fundamental aspects of this process. In the past, people used to recognise that climate adaptation is an essential architectural goal. Vitruve already said so. In his book "Principles of Human Geography", Ellsworth Huntington explains that climate is related to racial heritage and cultural development. The climate is one of the three principal factors determining a civilisation (Huntington 1951). This article focuses on human comfort and more particularly thermal comfort in urban public spaces. There are of course multiple ways to study the concept of human comfort in relation to public spaces. Our approach is based on the climatic factors intervening in our perception of the environment. It aims at complementing other levels of architectural questioning. Its main object is to valorize microclimate studies of the urban places in order to support sustainable development of the cities.

\section{OUTDOOR COMFORT}

\subsection{Target for sustainable cities}

Urban public space can never be regarded as a residual space between buildings. Thanks to its capacity to generate meetings and to support a mixing of the population, it is a fundamental space for the city social life. Moreover, public spaces take a large part in the definition of a life quality offered to all citizens. This is akin to the social target of sustainable development, which aim is reaching a greater social 
equity. For this reason, it is essential that urban public spaces are comfortable and attractive. Indeed, they are the place where collective values are built.

In everyday life, we experiment that the atmospheric conditions stimulate and vivify our activities certain days while at other moments they limit our physical and mental energy. The appropriation of a public space depends partly on the microclimatic factors increasing, limiting, modifying or directing its use. A study carried out in Norway showed that a suitable urban microclimatic design could extend the period of comfort during which Norwegian spend time outside by six weeks, in spring and in autumn. (Culjat \& Erskine 1998).

An other experiment, carried out by Nikolopoulou on 1431 people, examines how the thermal comfort affects use of a space. This English study on public places proves that there is a relation between the microclimatic conditions and the number of users in public places (Nikolopoulou et al. 1998, 2001). People's reactions to the microclimate are often unconscious but the use of outdoor spaces varies according to the climatic conditions. Therefore, limiting pedestrians' discomfort outside is one of the main targets that aim at increasing the occupation of urban places.

Just as the energy performances of a building depend on the climate, the urban microclimate strongly influences the city's energy consumption. The interaction of the climate and the city makes it possible to limit, directly and indirectly, diverse energy usages. The microclimatic parameters have a major influence on buildings consumption in the city. However, $41 \%$ of the totality of energy used in the European Union and an equivalent proportion of generated pollution is used for buildings (Steemers 2003). Other aspects of the urban environment also play a significant role, in relation to energy. Urban transport is the second factor of energy consumption in cities. Moreover, it creates big problems of air pollution, noise and congestion (Steemers 2003). When one limits the sources of outdoor discomfort, walking, bicycling and public transports are promoted. Therefore, to develop more ecological transport types than cars, it is necessary to requalify public spaces for pedestrians and cyclists. This implies studying the problems of outdoor comfort.

An ecological building is often represented as a nice house, which uses few resources and is located in the nature, far from urban concentrations and their harmful effects. Although this image may seem ideal, it is misleading. This building needs many infrastructures. In addition, it will require much more energy, to provide equal services, than a banal building downtown (heat island effect, party walls). A compact typology is beneficial and allows energy savings. The first total factor of energy savings is the density of buildings (Cretton 2000). Developing the city's image and attracting inhabitants downtown present many social and environmental qualities. Since pedestrians play an irreplaceable role in urban animation, we have to invest in them. This will prevent, in the long run, a policy of urban revival. Comfort in urban public spaces becomes then a hinge between the local aim of ensuring inhabitants wellbeing and the global goal of urban fabric density.

Finally, an urban design based on the study of the microclimate does not only improve pedestrian comfort in cities but also the building's interior quality (for example, it helps decreasing their energy consumption). The ventilation of a place does not only reduce the risks of pollution of public spaces. It also increases the air quality in the buildings which are next to it. And it allows replacing a potential system of air-conditioning by natural ventilation.

Studying the microclimate at the level of outdoor places is one of the grounds for a sustainable town planning. For example, the legislation of San Francisco recognises this positive influence of comfort in public spaces. It imposes that new buildings do not create awkward shades on public space and that the wind is limited to $5 \mathrm{~m} / \mathrm{s}$ on the ground level, during $90 \%$ of time, in the outdoor relaxation public spaces (Bosselmann et al. 1988). Adapted strategies of design can really optimise urban climate and outdoor comfort.

\subsection{Influence of the human perception}

The feeling of comfort is the expression of an individual's wellbeing in his environment. The perceived space is always a reduction of the real space. The human perception system utilises filters to analyse a space. A few elements are perceived and only some of them are memorised. Thus, people keep a simplified and subjective picture of reality. For the same urban environment, comfort can vary according to a combination of people's physical, physiological, psychological, sociological and cultural factors (CERMA 2002).

Individuals feel an immediate attraction or repulsion when discovering a place. For example, a crossroads filled with cars may induce repulsion. In contrast, seeing a square with trees gives a lively impression and welcomes pedestrians. Feelings of comfort come from a total perception of our environment. This global impression is the result of a synthesis of objective and subjective feelings. It implies that people have difficulties in recognizing the cause of their dissatisfaction. 
People are very sensitive to discomfort. Moreover, under extreme climatic conditions, the microclimate becomes the most significant parameter for the use of a space. (Nikolopoulou et al. 2000). Thus, the people do not seek the sites that get optimal physiological balance but avoid situations they feel uncomfortable.

The parameters influencing the pedestrian comfort cannot be easily quantified because of their nature, their number and their interdependence. This does not mean, however, that these parameters cannot be studied or that their influence is negligible. But, architects and town planners have to adequately analyse daily lived urban space to integrate these parameters in their creative process.

In practice, many factors must be taken into account in the definition of comfort beside the physiological approach. Human subjectivity renders the calculation of these factors difficult. However, some psychological comfort parameters have to be considered.

Since a few years, the importance of the adaptation in the process of comfort has been largely identified (Baker 2000, de Dear et al. 1997, Nikolopoulou \& Steemers 2003). Adaptation can be interpreted as a gradual reduction in the response of a living organism to a repeated environmental stimulation. Opportunity for adaptation is the real and perceived freedom to adjust to its local environment or change it. This adaptation opportunity decreases the comfort requirements of the subject even though no action is carried out. There is, thus, a psychological aspect in this adaptation process. In our comfortable lives, it is easy to forget the vital role of adaptation for species survival. However, the success of this adaptation capacity is remarkable.

Thermal comfort is the only type of comfort that will be thoroughly analyzed in this article. Mechanical wind comfort takes a large place in outdoor comfort. It is important but it is not the subject of this article. Visual comfort, acoustic comfort and olfactive comfort can also be determining in some kinds of surroundings. However, the thermal satisfaction and the mechanical strength of the wind are the two main microclimatic elements for outdoor comfort. Besides, these two comfort components are strongly influenced by town planning and can be easily modified.

\section{OUTDOOR THERMAL COMFORT}

\subsection{Differences between indoor and outdoor comfort}

The majority of the studies carried out on thermal comfort treat only indoor conditions. The few works that extend the indoor comfort criteria to outdoor comfort are purely physiological and steady. It is, however, obvious that indoor and outdoor comfort cannot be solved by the same approaches. First, the two principal climatic parameters for external comfort are wind and radiation, which are both excluded from indoor studies. Moreover, outside, people generally wear different clothes according to the season. Other variables -such as the kind of activities- can also create a significant physiological difference in thermal comfort. As people pass most of the time indoor, the steady models are useful to analyse indoor thermal comfort. But these models tend to overestimate outdoor discomfort. This difference is even larger for cold external conditions than for hot climates. For example, a person leaving a comfortable zone for a cold outdoor space will reach a steady state only after several hours. By opposition, in a hot external environment, the same person will reach it in less than 30 minutes. Unsteady models have thus to be used for external comfort under cold conditions (Höppe 2002).

Lastly, people's subjective response to the surrounding conditions is very different indoor and outdoor of the buildings. Various studies based on pedestrians interviews show that people accept much more diverse thermal conditions outside than inside (Nikolopoulou et al. 1998, 2001, Höppe 2002). People's psychological reactions to outdoor environment are fundamental. Indeed, psychological adaptation is much stronger outside than inside. This adaptability is, however, generally forgotten.

\subsection{Parameters of outdoor thermal comfort}

Criteria to asses comfort are all based, in the literature, on thermal physiological balance of the human body. The heat balance is a significant component of outdoor comfort. It influences the thermal feeling of outdoor comfort. However, it has been proven that this approach is absolutely insufficient to define the criteria of external comfort. (Nikolopoulou et al. 2001, Höppe 2002). Psychological adaptation is a variable of equal importance (Nikolopoulou et al. 2000). Consequently, the criteria influencing people's psychological adaptation must be integrated in any outdoor comfort evaluation method.

In the context of thermal comfort, adaptation covers all the processes that people can initiate so that their thermal needs coincide with the environmental conditions. Let us analyse with precision this adjustment process. Human thermal adaptation includes three distinct processes: behavioural adjustment (or physical adaptation), physiological adjustment and psychological adjustment (Baker 2000, de Dear et al. 1997, Nikolopoulou \& Steemers 2003).

Behavioural adaptation gathers all the consciously or unconsciously actions aimed at modifying someone corporal thermal balance. This kind of adaptation can be done in three different ways: personal 
adjustment (clothing, activity, posture, food, drinking, change of localisation), environmental adjustment (modification of the environment itself, for example opening a parasol) and cultural adjustment (dress code, society induced activities e.g. siesta time). The effects of physical adaptations can generally be evaluated quantitatively.

Physiological adaptation is a physiological response of the body. It tends to decrease the stress related to an uncomfortable situation. In this case, it is called physiological acclimatisation. This type of mechanism is crucial in extreme climatic conditions. However, its impact is negligible for the object of this research.

Psychological adaptation is a modification of the perception of sensory informations. This type of adaptation can be connected to the "habituation" concept found in psychophysics. This notion corresponds to reduction of the intensity feeling, in the event of repeated exposures to the same environmental stress. Thermal perceptions depend directly on past experience and space users expectations. Psychological adaptation is very difficult to quantify.

Many authors affirm the importance of the subjective point of view for thermal comfort evaluation. However, they bypass the issue and focus on quantitative methods (tables, graphs or formulas). Recently, some authors specifically studied psychological comfort but put the quantitative evaluation aside. We intend to evaluate quantitatively the pedestrians' thermal balance and qualitatively the criteria which influence their psychological adaptability. This combining of quantitative and qualitative parameters allows to improve the possibilities of thermal comfort of public spaces.

\section{CRITERIA OF OUTDOOR COMFORT}

\subsection{Quantitative criteria}

For many authors, it is impossible to express the human physiological comfort on the bases of a single parameter such as temperature or air speed. It is essential to combine the effect of different climatic factors on the human energy balance in only one formula. Traditionally, there are six parameters to take into account for evaluating physiological thermal comfort (Givoni 1969, Fanger 1970): four climatic parameters (air temperature, air speed, radiation and relative humidity) and two physical parameters (activity and clothing).

Most of the recommended comfort indices areworked out for interior conditions and not applicable outside. What's concerns outdoor thermal comfort, a really interesting evaluation method is the Olgyay's Bioclimatic Chart, which is based on outdoor studies and not on indoor experiments (Olgyay 1963). This chart draws the zone of external comfort for a situation without wind or direct solar radiation (i.e. in the shadow). Olgyay's Bioclimatic Chart covers a broad range of temperature, moisture, wind speed and solar radiation levels. It can only be directly applicable in outdoor situations, for the United States inhabitants, equipped with indoor clothing, engaged in a sedentary activity or a very light work, at an altitude not exceeding $1000 \mathrm{ft}(=305 \mathrm{~m})$ above the sea level and for a latitude of $40^{\circ}$. But, the comfort zone must be adapted to any modification of one of these parameters. The graph below gives Olgyay's chart adapted to a moderate European climate.

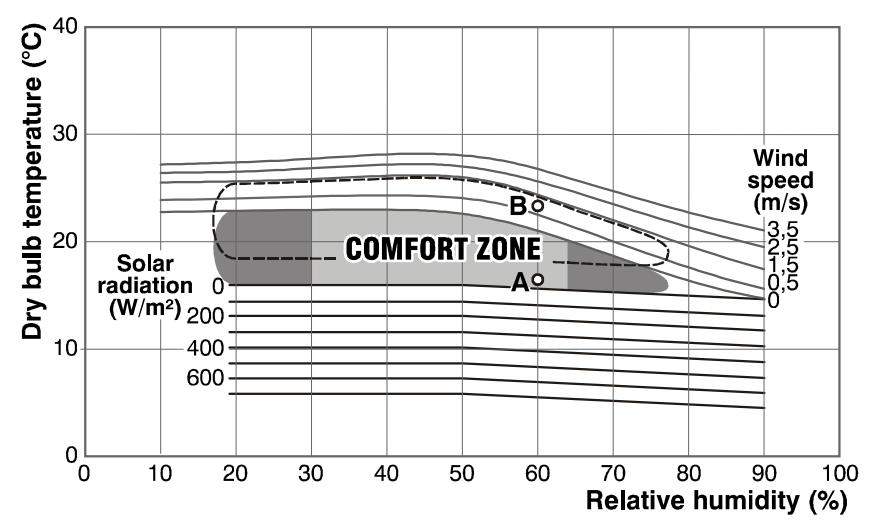

Figure 1. Olgyay's chart for moderate European climates.

It should be noted that Olgyay proposes a bioclimatic diagram encompassing two comfort zones: a summer and a winter zone. This remark shows that he partly takes account of people's adaptation to the season. On the figure 1 , point $\mathrm{A}$ is in the winter comfort zone while point B is in the summer comfort zone.

The interest of Olgyay's approach resides in combining an analytical and a diagnostic tool. This chart shows how the uncontrollable change of one factor can be compensated for by the controlled variation of another.

For example, in summer, a temperature of $27^{\circ} \mathrm{C}$ and a relative humidity of $60 \%$ without wind and direct solar radiation create an uncomfortable situation. A cooling of about $3^{\circ} \mathrm{C}$ would ensure comfort but, if temperature is uncontrollable, ventilation (air velocity of about $1.5 \mathrm{~m} / \mathrm{s}$ ) should be provided to ensure comfort.

Another example: with a temperature of $17^{\circ} \mathrm{C}$ in winter and a relative humidity of $40 \%$, a person is in the comfort zone. But, if this same person receives direct solar radiation of about $500 \mathrm{~W} / \mathrm{m}^{2}$, the whole of the comfort zone will be lowered to that line and the person is now in a too hot environment. Comfort conditions could be restored either by eliminating this radiation (ie, shading) or by ensuring about 0.5 $\mathrm{m} / \mathrm{s}$ air movement.

Among the four significant microclimatic elements that affect the body energy balance, only ra- 
diation (solar and terrestrial) and wind can be significantly modified by a judicious design (Brown \& Gillespie 1995).The compensation effect of wind speed and solar radiation in outdoor spaces can be easily estimated on the basis of this traditional simple tool.

For outdoor conditions, a scale of horizontal irradiance (in $\mathrm{W} / \mathrm{m}^{2}$ ) is given (figure 1), showing that an irradiance of $70 \mathrm{~W} / \mathrm{m}^{2}$ is equal in effect to a temperature increase of $1{ }^{\circ} \mathrm{C}$. This is an approximation, but it can be immediately related to the solar radiation data available in this form.

The figure below is Olgyay's interpretation of his chart to explain how sunshine and wind can be used to extend the comfort zone. The advantage of this drawing is to be very expressive for the architects.

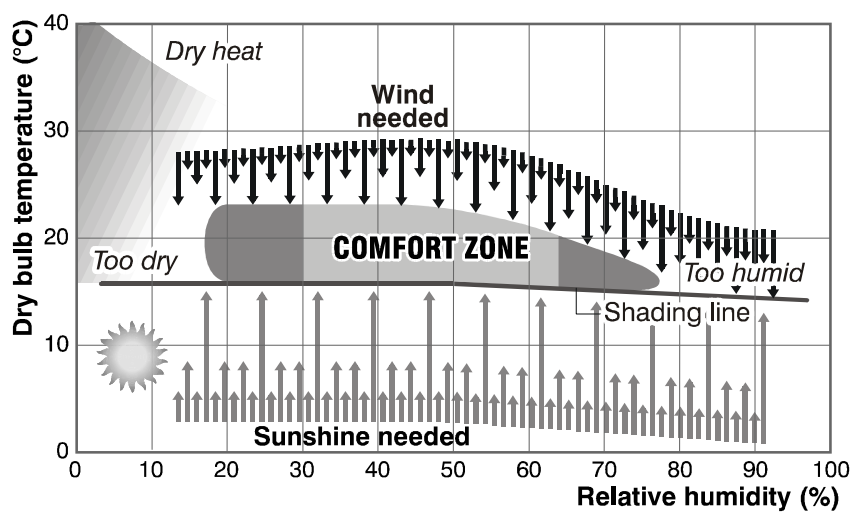

Figure 2. Interpretation of Olgyay's Bioclimatic Chart.

Nevertheless, it is significant to recall that bioclimatic design is characterized by the use of positive climatic parameters and by the protection from negative climatic elements. In the same way, the microclimatic design for human comfort can be summarized in two fundamental rules: to profit from the climate and to protect itself from the climate. The figure 2, given by Olgyay, represents the two easiest means to benefit from the climate: to profit from the sunshine in cold zones and to profit from ventilation in hot zones. But this drawing does not show the importance to be protected from the negative climatic elements. However, in uncomfortable situations, the first action to be posed is to remove the cause of discomfort. Thus, we cannot forget to protect cold zones from the wind and to protect hot zones from the direct solar radiation.

The main advantage of the bioclimatic chart over the single-figure comfort indices is that, whilst integrating the effects of the four environmental factors in terms of human thermal comfort, it allows the dynamic handling of these.

However, this tool shows means of improving physiological comfort. But it does not quantify its discomfort. Moreover, it does not take account of the unsteady character of outdoor climate.
Olgyay was the first to connect climate and comfort in a graphic way. Thereafter, the psychometric chart was spread like one of the basic tools in the studies of interior comfort. In 1980, Arens modified the Olgyay's Bioclimatic Chart to integrate it in the psychometric chart (Docherty \& Szokolay 1999).

It would be judicious to use Olgyay's chart to evaluate the probability of physiological comfort reached in a particular square under given circumstances. These results need to be evaluated in connection with the qualitative criteria. As a result, in function of their frequent activities, you know which climatic elements to modify to ensure thermal comfort, during longest period of time, to the majority of the space users.

However, the quantitative limits given by Olgyay's chart are too narrow to indicate the physiological discomfort for outdoor situations because it does not take climatic variations into account. Evans has recently introduced a graphic tool to study thermal comfort, answering variations in temperature (Evans 2003). The development of a physiological performance standard from quantitative information for outdoor thermal comfort is a complex process. And it is still an object of research (Bosselmann et al. 1995). The current problem is that it does not exist any unsteady comfort index, internationally accepted, to solve this problem.

\subsection{Qualitative criteria}

Psychological adaptation is one of the essential elements that define outdoor comfort. However, the factors influencing this human adaptation are not completely subjective. We raise five essential parameters of psychological adaptation: relation with the context, perception of potential control, microclimatic environments diversity, continuity of climatic conditions and naturality of the place.

\subsubsection{Relation with the context}

Oseland proved that thermal comfort depends on the context. It showed that the same group of people felt different comfort levels in three different contexts: a climatic room, their work place and their home (becoming increasingly tolerant). They accepted a lower temperature of comfort of $3 \mathrm{~K}$ in their house than in the climatic room (Oseland 1994). It is obvious that people become even more tolerant in outdoor conditions.

There are two large schools of thought on indoor thermal comfort: those who estimate that thermal comfort is best expressed by a neutral environment, coming from a balanced state, and those who ensure that comfort can be reached within a broad range of thermal perceptions. The latest is based on the assumption that human adaptation is significant. The 
first school uses studies in climatic room to ensure its theory: the static model, which covers studies as known as the Fanger's PMV model, the ASHRAE Standard 55 and the International Standard 7730 (ISO). The second school, represented by Auliciems and Nicol, is based on experiments in real buildings and is known as the adaptive method (Auliciems 1989, Nicol 1993). Adaptive approach consists in defining interior temperature as strongly connected to outdoor experience and people's control capacities. A scientific study based on a lot of buildings in the world (de Dear et al. 1997) shows that there are two methods for indoor thermal comfort because there are two different studies contexts. Moreover, it proves that in HVAC buildings, the Fanger's model (PMV) is remarkable to predict comfort but that, for naturally ventilated buildings, it is preferable to use a method of adaptive comfort. Fanger's method allows to integrate indoor behavioural adaptations (clothes, activities, etc.) while physiological adaptations can be neglected under normal climatic conditions. Thus, these two types of comfort method in buildings show that the context strongly influences human psychological adaptation opportunity.

Since thermal comfort is strongly contextual, outdoor thermal comfort of a public space depends on its insertion in a nurture. To solve this problem, it is necessary to study the natural, built and human contexts, according to localisation, season, potential activities, etc. It is necessary to create spaces integrating the most probable activities, the time that people will pass there and their climatic preferences in the conception work. No decision can be made according to microclimate without taking account of the place, its temporalities and its usage. When and how a space will be used by inhabitants matters in choosing which type of action should be realised on this specific environment. For example, to each season corresponds a different appropriation of public spaces. It is, then, judicious to conceive different adaptation possibilities for each season.

This fundamental lesson could have been drawn from the past. Climatic architecture and town planning show that there is no valid solution for all situations. Each project must be imperatively integrated in its context.

\subsubsection{Perception of potential control}

The perception of potential control is one of the most essential elements of thermal comfort. Paciuk affirms that unpleasant stimuli are less irritating when the subjects perceive that they can control them (Paciuk 1990).

Interactive adaptation seldom takes place outside. However, movable components -such as parasols or windbreaks- allow spatial and temporal variations to adapt to the climate. These elements offer a direct control appropriateness on the environment and are generally appreciated by space users.

But, the possibility of moving towards another thermal ambience is also perceived like a possibility of control over our thermal balance. People sitting in squares under physiologically uncomfortable conditions, feel more comfortable if they are free to leave this place as soon as they wish to rather than if they are waiting for somebody. (Nikolopoulou \& Steemers 2000). When people have chosen to go to a place, they are able to move whenever they want. By this action, they can thus control their thermal environment.

The experience duration of the users also influences their perception of control. A discomfort experience is not seen negatively if the individuals anticipate that its duration is short (for example leaving a car to join a building in winter). In contrast, it is a critical aspect for squares or resting places use since people modify the time they spend there according to their comfort needs. (Nikolopoulou \& Steemers 2000).

\subsubsection{Diversity of microclimatic environments}

Squares offering diverse zones with shade and sun are used for a longer time than those presenting only one type of atmosphere (Nikolopoulou \& Steemers 2000).

Someone may prefer either to sit in the sun or in the shadow of a building, refreshed by a breeze or protected from the wind, in contact with the sky or under arcades. The cities have always been designed to provide these choices. And they can still offer it. Places encompassing different atmospheres create a feeling of increased comfort for the users. Indeed, they allow to move from one zone to another. Certain zones will obviously be preferred at certain seasons or times of the day. Our objective is to create a rich and varied urban environment.

\subsubsection{Continuity of climatic conditions}

A Norwegian study shows that the minimal comfort temperature is of $11^{\circ} \mathrm{C}$ in autumn but of $9^{\circ} \mathrm{C}$ in spring. Thus, people's satisfaction varies with their expectations and is driven by past experience. Usually, the temperature is colder during the period preceding Spring than the period preceding Autumn (Culjat \& Erskine 1998).

The pedestrian's expectations and its recent memories have a twofold importance. First, they influence the person's dressing and play thus a role on the physiological balance. Second, they prepare her psychologically and influence her level of satisfaction. Past experience is not so related to the site because it depends on each person's story. However, it is possible to take the short-term experience into account. 
An abrupt change in the environment surrounding us is always difficult to accept. It is advised to create transition zones, so that the passage from a zone where people feel comfortable to a less neutral environment is done imperceptibly. Going from an uncomfortable zone towards a more comfortable one is easier to accept even though if the change is abrupt (Nikolopoulou \& Steemers 2000). The possibilities of creating transition spaces are infinite. They depend on climate, building forms and town planning.

\subsubsection{Naturality of the place}

Naturality describes an environment free of artificiality. The natural character of a place is an essential parameter for people's comfort. Significant environment modifications are better tolerated in spaces where the climatic changes appear naturally than in other zones (Nikolopoulou \& Steemers 2003).

Modern life isolates us more and more from the natural world. These questions will become critical considering the growth of urbanisation. This assertion has two corollaries:

- we should increase the natural elements in our cities.

- we have to conceive spaces that offer similar characteristics to those provided in the natural world.

There are two types of natural elements that fit easily in an urban environment: vegetation and climatic elements. The presence of a sunbeam or air movements can be attracting for people too accustomed to artificial environments. An essential characteristic of the natural world is its variability in time and space. It is essential to create opening opportunities to change in our rigid surroundings.

Many studies show that natural elements are beneficial for humans. For example, natural light is better adapted to human eye than artificial light is (Reiter \& De Herde 2001).

Ulrich discovered that hospitals patients able to see a natural landscape recover more quickly than those facing a white wall (Ulrich 1984). A study in Norway by Fjeld compares two groups of people working in offices, one decorated with beautiful plants and the other without vegetation. Tiredness, headaches and concentration problems decreased by $23 \%$ in the office with a pleasant vegetation (Fjeld 1998). These studies prove that vegetation is an essential element for the comfort of human beings.

Holiday makers' choices of outdoor leisure activities frequently expose them to high discomfort levels. For examples, tanning under extreme sun, skiing, climbing a mountain, etc. How to reconcile this observation with our definition of thermal comfort? These extreme environmental circumstances bring us a salutary contrast in comparison with our constant and artificial built-up areas (Baker 2000). Human beings have a real need for naturality and in particular for environmental stimulation.

Comfortable conditions are often defined as a neutral state. However, environmental stimulation is one of the reasons why people go outside. When the environment presents few thermal stresses, the search for environmental stimulation becomes the first reason to do so (Nikolopoulou \& Steemers 2003). Non-neutrals conditions and an adaptation opportunity bring together a greater satisfaction to occupants.

Pedestrians do not only tolerate climate variations but even desire them. Variable environments are often preferred to static ones. Environment variability is necessary for people who spend most of their day in a room's monotonous ambience (Baker 2001). There are many temporal and spatial scales to create this variability.

\section{CONCLUSION}

One of the essential targets for cities' sustainable development is creating a beneficial microclimate in urban public spaces, thanks to adequate architectural and urbanistic design. Indeed, microclimatic parameters have multiple influences on cities characteristics and people's behaviour. Positive effects of an urban design that accounts for people's comfort are:

- the life quality improvement in cities' public spaces (social equity, etc).

- the increase of the use of urban squares.

- the reduction of buildings and public spaces energy consumption (ventilation, façade exposure, etc.; decrease of cars' traffic, use of bicycles and public transportation, encouraging pedestrians, etc.).

- the limitation of the environmental harmful effects (air pollution, etc.).

- the valorisation of the city's image in order to attract inhabitants downtown. Let us recall that the first factor of energy savings is the density of buildings.

Outdoor places present few constraints for users. Pedestrians choose to be there. It would be, however, erroneous to conclude that outdoor comfort is not significant. Indeed, the studies presented clearly show that the microclimate is one of the influence factors of the public spaces use. Perceived comfort triggers a desire for going outside. Moreover, the perception of comfort influences the decision of stopping in a space rather than crossing it. However, when someone decides to go outside and sit down in an outdoor space, he is prepared to make de best of 
the external conditions. Psychological adaptation takes then all its importance. In fact, human beings avoid discomfort but do not seek optimal comfort.

Comfort is a global feeling of wellbeing or discomfort. Consequently, it is difficult to know where a dissatisfaction comes from. Comfort is influenced by objective and subjective factors. A quantitative approach is insufficient to describe the conditions of outdoor comfort. Our new comfort approach consists in joining physiological to psychological criteria, in order to support an optimal use of climatic elements in public spaces. This has never been done yet. Any study taking account of urban public places quality has to integrate quantitative and qualitative comfort parameters, from the draft on.

The physiological parameters of thermal comfort are temperature, air speed, radiation, relative humidity, people's dressing and activities. The problem of thermal comfort indices is to fix too strict quantitative limits. It is justified to give limiting values to physiological outdoor discomfort. But no system currently exists that specifies these values in an exact way. An interesting method is Olgyay's chart. It implies an analytical and diagnostic study.

The physiological and psychological aspects of comfort are complementary and not contradictory. One cannot limit thermal comfort to thermal neutrality. It is necessary to consider a range of possible thermal feelings associated with the freedom to control our environment and adapt ourselves.

Various psychological criteria of outdoor human comfort are updated in this study. Outdoor thermal comfort depends in particular on the following factors:

- importance of relation with the context, in time and space (type of appropriation, activities, etc.).

- perception of potential control: movable components and possibility of localisation change.

- diversity of microclimatic atmospheres.

- continuity of surroundings (transition spaces, etc.).

- naturality of the place: presence of vegetation, environmental stimulation and variability of the climatic conditions.

We must be conscious of the significant implications of these psychological elements on people's comfort. Public spaces' designers should take account of these parameters in order to improve our cities quality.

We advise to evaluate a situation starting from Olgyay's Bioclimatic Chart on one hand and the qualitative criteria found in this study on the other hand, to determine what are the advantages and weaknesses of a given situation. A careful design of urban spaces adapted to the microclimate can provide, during most of the time, a protection against negative aspects and an exposure to positive aspects of the climate, to the majority of the users.

In spite of the complexity of the mentioned interactions, it is possible to consider some design criteria which will influence the comfort of pedestrians in urban sites. It is already possible to modify the comfort conditions of a place by:

- modifying its microclimate by adaptation of one of its physical parameters (in general the solar radiation or the wind).

- stimulating adapted activities.

- increasing perceived control (for example by devices such as parasols).

- proposing several climatic atmospheres in the same place (shade and sun, wind and shelter, etc.).

- creating transition spaces between different zones (inside/outside, etc.) to attenuate contrasts compared to recent past experience and to improve continuity of the climatic conditions.

- increasing its naturality through vegetation or environmental stimulation.

We affirm that outdoor thermal comfort can only be defined by a combination of qualitative and quantitative criteria. One should evaluate quantitatively the pedestrians' thermal balance and qualitatively the criteria influencing their psychological adaptability. This set of criteria should be used in order to draw judicious conclusions to improve thermal comfort in public spaces.

\section{ACKNOWLEDGMENTS}

The research presented in this paper is financed by Brussels ("Région de Bruxelles-Capitale"). It was written within the framework of a convention between Brussels ("Région de Bruxelles-Capitale") and the research unit "Architecture et Climat" of the "Université Catholique de Louvain". "Architecture et Climat" is a research centre in architecture and architectural engineering. Its objective is to promote sustainable development and particularly an adequacy between climate, buildings and inhabitants.

\section{REFERENCES}

Auliciems, A. 1989. Thermal comfort. In Buildin Design and Human Performance. New York: Ruck.

Baker, Nick 2000. We are all outdoor animals. In Koen Steem ers and Simos Yannas, Architecture City Environment, Proceedings of PLEA 2000. London: James and James.

Baker, N. 2001. Designing for comfort, Recognising the Adaptive Urge. Cambridge: Martin Center for Architectural and urban Studies. 
Bosselmann, P. \& Dake, K. \& Fountain, L. \& Kraus, L. \& Harris, L. \& Harris, A. 1988. Sun, Wind and Comfort: Study of Thermal Comfort in San Francisco. Berkeley: Centre for Environmental Design Research, University of California.

Bosselmann, Peter \& Arens, Edward \& Dunker, Klaus \& Wright, Robert 1995. Urban form and climate, case study, Toronto. Journal of the American Planning Association 61 (2).

Brown, R.D. \& Gillespie, T.J. 1995. Microclimate Landscape Design, creating thermal comfort and energy efficiency. Canada: John Wiley \& Sons.

CERMA 2002. Proceedings of the First International Work shop on Architectural and Urban Ambient Environment, Nantes: G. Hégron.

Cretton, Paul 2000. Ecobilans. Les infrastructures : quels impacts? Cycle d'études postgrades et master européen en architecture et développement durable. Louvain-la-Neuve.

Culjat, B. \& Erskine, R. 1998. Climate-responsive social space: a Scandinavian perspective, In J. Mänty et N. Pressman (eds), Cities Designed for Winter. Helsinki.

de Dear, Richard \& Brager, Gail \& Cooper, Donna 1997. Developing an Adaptive Model of Thermal Comfort and Preference, Final Report. ASHRAE RP- 884. Ashrae.

Docherty, M. \& Szokolay, Steven V. 1999. Climate analysis. PLEA notes 5: University of Queensland.

Evans, J.M. 2003, Evaluating comfort with varying temperatures: a graphic design tool. Energy and Buildings 35 (1):8793

Fanger, P.O. 1970. Thermal comfort, analysis and applications in environmental engineering. USA: Mc Graw-Hill Book Company.

Fjeld, T. 1998. The Effect of Indoor foliage plants on the Health and Discomfort Symptoms among Office Workers. Indoor Built Environment 7.

Givoni, B. 1969. Man, Climate and Architecture, UK: Elsevier Architectural science series.

Höppe, Peter 2002. Different aspects of assessing indoor and outdoor thermal comfort. Energy and Buildings 34.

Huntington, Ellsworth 1951. Principles of Human Geography. 6th edition. New York: John Wiley and Sons.

Nicol, F. 1993. Thermal comfort- A Handbook for Field Studies Toward an Adaptive Model. London.

Nikolopoulou, M. \& Baker, N. \& Steemers, K. 1998. Thermal comfort in outdoor urban spaces. In Proceedings PLEA 1998: Environmentally Friendly Cities. James\&James.

Nikolopoulou, M. \& Steemers, K. 2000. Thermal comfort and psychological adaptation as a guide for designing urban spaces. In Proceedings of PLEA 2000. Cambridge.

Nikolopoulou, M. \& Baker, N. \& Steemers, K. 2001. Thermal comfort in outdoor urban spaces: understanding the human parameter. Solar Energy 70 (3): 227-235.

Nikolopoulou, Marialena \& Steemers, Koen 2003. Thermal comfort and psychological adaptation as a guide for designing urban spaces. Energy and Buildings 35 (1):95-101.

Olgyay, Victor 1963. Design with climate, bioclimatic approach to architectural regionalism. New Jersey: Princeton university press.

Oseland, N.A. 1994. A within-groups comparison of predicted and reported thermal sensation votes in climate chambers, offices and homes. In Healthy Buildings 1.
Paciuk M., 1990. The role of personal control of the environ ment in thermal comfort and satisfaction in workplace. In Coming of age. USA: EDRA.

Reiter, Sigrid \& De Herde, André 2001. L'éclairage naturel des bâtiments. Belgique : Ministère de la Région Wallonne.

Steemers, Koen 2003.Energy and the city: density, buildings and transport. Energy and Buildings 35:(3-14).

Ulrich, R.S. 1984. View through a Window may influence Recovery from Surgery. Science 224.

Zold, Andras 1999. Thermal comfort in sunspaces. In PLEA'99, Sustaining the future: energy - ecology - architecture, proceedings of the plea'99 conference. Brisbane. 